\title{
Response to "Comment on Retrospective Claims Analysis Indirectly Comparing Medication Adherence and Persistence Between Intravenous Biologics and Oral Small-Molecule Therapies in Inflammatory Bowel Diseases"
}

\author{
Kellyn Moran · Kyle Null · Zhongwen Huang • Trevor Lissoos • \\ Sunanda Kane
}

Received: February 18, 2020 / Published online: March 15, 2020

(C) The Author(s) 2020

Keywords: Inflammatory bowel disease; IBD; Intravenous biologics; Oral small-molecule therapies

We are writing this is in response to the "Comment on Retrospective Claims Analysis Indirectly Comparing Medication Adherence and Persistence Between Intravenous Biologics and Oral Small-Molecule Therapies in Inflammatory Bowel Diseases," and we thank the authors for their interest in our work. In our analysis, the objective was to gain insights into the potential impact of treatment-related factors (e.g., route of administration) on medication utilization, including persistence and adherence to medication.

We acknowledge that there can be variability in adherence to biologics and in how it is measured, and we pointed this out in our introduction.

Although we were comparing two drugs with different indications, we recognized the limitations of this strategy, and therefore attempted a

K. Moran · K. Null · Z. Huang · T. Lissoos U.S. Medical Affairs, Takeda Pharmaceuticals U.S.A., Inc., Deerfield, IL, USA

S. Kane $(\bowtie)$

Division of Gastroenterology and Hepatology

Department of Medicine, Mayo Clinic, Rochester,

MN, USA

e-mail: Kane.Sunanda@mayo.edu novel approach to indirectly adjust for these disease differences. We feel we were transparent about the limitations of this comparison, and recommended future studies in which comparison within disease states would be possible.

In the Comment letter, the authors state "the authors conclude that after adjustment, adherence was higher with infusions than oral medications [1]. These results are in contrast to findings from previous well-conducted studies $[2,3]$. . We disagree that the two studies cited by the Comment authors provide evidence that adherence is higher with oral medications than with infusions. In Pope et al. [2] there is no comparison between oral and intravenous administration. This study was a pooled analysis of two open-label extension studies and all patients were on tofacitinib, and therefore, all were on oral treatment. In Harnett et al.'s analysis [3] the main mode of administration comparator was subcutaneous injections and not infusions. In our analysis, we did not draw any conclusions about the difference in medication adherence/persistence between subcutaneously administered and oral medications. The referenced study also showed no difference in mean persistent days and the proportion of patients persistent at 12 months (including in the adjusted analysis) across the studied medications; adherence outcomes were also similar across these medications (with the exception of abatacept). 
Neither of the above studies referenced by the Comment authors compares oral administration vs infusion administration, as our analysis did, and thus are not apt comparisons. Comparing adherence rates among oral medications vs infusion medications is a concept that has been evaluated in prior studies. Previous literature comparing oral administration vs infusion administration (cited in our introduction; [4]) summarized that adherence rates are higher in patients receiving either intravenous or subcutaneous therapies compared with patients receiving oral therapies. This concept is expounded on in a retrospective database study [5] that observed an adherence rate of $96 \%$ in patients taking infliximab for Crohn's disease, compared with adherence rates of $40-50 \%$ that have been reported for daily oral medications. Further studies evaluating US claims data in patients with rheumatoid arthritis found that adherence rates were $80.9 \%, 68.4 \%$, and $63.7 \%$ among patients who received infliximab (administered intravenously), etanercept (self-administered subcutaneously), and methotrexate (administered orally) [6]. Taken together, these studies agree with our findings that adherence is higher with infusions than with oral medication. However, it is important to note that other factors, such as drug effectiveness, can influence adherence and persistence.

The Comment authors continue: "Although the authors of the paper noted that there are several reasons for discontinuation that pertain to each disease' as a limitation of the study [1], no discussion of reasons nor the important differences between rheumatoid arthritis and inflammatory bowel disease patient populations was included in the manuscript, such as age of the patients, presence of comorbidities, and number of concomitant therapies."

Although we did not expand on the differences between the rheumatoid arthritis and inflammatory bowel disease populations, we did acknowledge that these differences exist, and highlighted these differences as a limitation of our methodology. We agree with the responders that there are critical differences between these populations, including the ones they mention as well as others (i.e., differences in effectiveness and safety across indications, dosing, dose escalation).

The Comment authors state: "The study also failed to recognize tofacitinib dosing differences between the two diseases, both in terms of dose strength and overall posology."

We appreciate the mention of the dosing differences of tofacitinib in rheumatoid arthritis and ulcerative colitis. Because there is evidence that multiple doses per day are generally associated with worse patient adherence (including in immunologic diseases [see [4, 7] and from our introduction], and that twice-daily dosing of tofacitinib is required per label for ulcerative colitis, but can be either once-daily or twicedaily for rheumatoid arthritis, tofacitinib adherence/persistence in ulcerative colitis may be lower in real-world evidence than what was projected from using the rheumatoid arthritis data in our study (the observed difference could actually be greater). To quote from our article: "Dosing schedule complexity has also been associated with poor adherence to oral medications [8]. In fact, once-daily dosing was associated with significantly better adherence rates than twice-daily dosing [9]."

The Comment authors continue: "It is also noteworthy that tofacitinib is indicated for UC, in contrast to vedolizumab and infliximab, which have indications for both Crohn's disease and UC, reiterating the inappropriateness of these comparisons, which included patients with UC and also patients with Crohn's disease."

We acknowledge that tofacitinib is only approved in ulcerative colitis and not Crohn's disease and that we did not separate data for ulcerative colitis and Crohn's disease in our analysis; however, since we were performing an indirect comparison, we used infliximab to adjust for potential disease differences between rheumatoid arthritis and inflammatory bowel disease. Additionally, because persistence and adherence are generally worse in Crohn's disease than in ulcerative colitis [10], this might have diminished the effect we observed for infliximab and vedolizumab in our study.

The Comment authors concluded: "that there was wide variability in the concept of adherence as well as in its measurement [11]. 
The choice of methods used might therefore be expected to affect the conclusions of a study such as that presented in Moran et al. Of note, although two methods were used to evaluate adherence, significant differences between vedolizumab/IBD and tofacitinib/RA were observed only for one of them after the adjustment method was applied [1]."

We agree that the methods of operationalizing adherence vary widely in the literature, and so we used two methods to triangulate on the answer. We chose to highlight the proportion of days covered (PDC) result because it is the more common metric used in quality measures and is generally more accepted in adherence literature. Ultimately, PDC and cumulative days with gaps at least $20 \%$ beyond expected interval (CG20) are different metrics. CG20 is a more conservative measurement of adherence because it only counts days beyond the 20\% threshold as non-adherent days; whereas PDC counts all days off therapy as non-adherent days. This could explain why the difference in adherence is non-significant for CG20 vs PDC.

In summary, we acknowledge that indirect comparison is not a common approach; however, we were transparent in communicating the limitations of the study in our original article. Despite our novel approach to evaluating differences in adherence, our findings agree with the literature and supporting evidence that shows adherence is higher in patients receiving intravenous therapies compared to oral therapies.

\section{ACKNOWLEDGEMENTS}

Funding. Funding for medical writing and editing services was provided by Takeda Pharmaceuticals U.S.A., Inc. No Rapid Service or Open Access fee was received by the journal for the publication of this article.

Medical Writing and Editorial Assistance. Medical writing and editorial assistance were provided by Reem Berro, PhD, and Sandi L. Lusk, BSc, CMPP, of inVentiv Medical Communications, LLC, a Syneos Health ${ }^{\mathrm{TM}}$ group company. This was funded by Takeda Pharmaceuticals U.S.A., Inc.

Authorship. All named authors meet the International Committee of Medical Journal Editors (ICMJE) criteria for authorship for this article, take responsibility for the integrity of the work as a whole, and have given their approval for this version to be published.

Disclosures. Sunanda Kane has served as a consultant for Samsung Bioepis. Kellyn Moran, Kyle Null, and Zhongwen Huang are employees of Takeda Pharmaceuticals, Inc., U.S.A, and may own stock or stock options. Trevor Lissoos is a former employee of Takeda Pharmaceuticals U.S.A, Inc.

Compliance with Ethics Guidelines. This is a response letter based on previously conducted studies and does not contain any studies with human participants or animals performed by any of the authors.

Peer Review. Please note, contrary to the journal's standard single-blind peer review process, as a letter this article underwent review by a member of the journal's Editorial Board.

Data Availability. Data sharing is not applicable to this article as no datasets were generated or analyzed for this letter.

Open Access. This article is licensed under a Creative Commons Attribution-NonCommercial 4.0 International License, which permits any non-commercial use, sharing, adaptation, distribution and reproduction in any medium or format, as long as you give appropriate credit to the original author(s) and the source, provide a link to the Creative Commons licence, and indicate if changes were made. The images or other third party material in this article are included in the article's Creative Commons licence, unless indicated otherwise in a credit line to the material. If material is not included in the article's Creative Commons licence and your intended use is not permitted by statutory regulation or exceeds the permitted use, you will need to obtain permission directly from the 
copyright holder.To view a copy of this licence, visit http://creativecommons.org/licenses/bync/4.0/.

\section{REFERENCES}

1. Moran K, Null K, Huang Z, Lissoos T, Kane S. Retrospective claims analysis indirectly comparing medication adherence and persistence between intravenous biologics and oral small-molecule therapies in inflammatory bowel diseases. Adv Ther. 2019;36:2260-72.

2. Pope J, Keystone E, Jamal S, et al. Persistence of tofacitinib in the treatment of rheumatoid arthritis in open-label, long-term extension studies up to 9.5 years. ACR Open Rheumatol. 2019;1:73-82.

3. Harnett J, Gerber R, Gruben D, Koenig AS, Chen C. Evaluation of real-world experience with tofacitinib compared with adalimumab, etanercept, and abatacept in RA patients with 1 previous biologic DMARD: data from a U.S. administrative claims database. J Manag Care Spec Pharm. 2016;22: 1457-71.

4. Bressler B, Haraoui B, Keystone E, Sette A. Optimizing use of tumor necrosis factor inhibitors in the management of immune-mediated inflammatory diseases. J Rheumatol Suppl. 2010;85:40-52.

5. Kane S, Dixon L. Adherence rates with infliximab therapy in Crohn's disease. Aliment Pharmacol Ther. 2006;24(7):1099-103.
6. Harley CR, Frytak JR, Tandon N. Treatment compliance and dosage administration among rheumatoid arthritis patients receiving infliximab, etanercept, or methotrexate. Am J Manag Care. 2003;9(6 Suppl):S136-43.

7. Vangeli E, Bakhshi S, Baker A, et al. A systematic review of factors associated with non-adherence to treatment for immune-mediated inflammatory diseases. Adv Ther. 2015;32(11):983-1028.

8. Herman ML, Kane SV. Treatment nonadherence in inflammatory bowel disease: identification, scope, and management strategies. Inflamm Bowel Dis. 2015;21(12):2979-84.

9. Srivastava K, Arora A, Kataria A, Cappelleri JC, Sadosky A, Peterson AM. Impact of reducing dosing frequency on adherence to oral therapies: a literature review and meta-analysis. Patient Prefer Adherence. 2013;7:419-34.

10. Khan S, Rupniewska E, Neighbors $M$, et al. Realworld evidence on adherence, persistence, switching and dose escalation with biologics in adult inflammatory bowel disease in the United States: a systematic review. J Clin Pharm Ther. 2019;44(4): 495-507.

11. Moots RJ, Haraoui B, Matucci-Cerinic M, et al. Differences in biologic dose-escalation, non-biologic and steroid intensification among three anti-TNF agents: evidence from clinical practice. Clin Exp Rheumatol. 2011;29:26-34. 